\title{
Relationship between composite structures and compressive properties in CuZr-based bulk metallic glass system
}

\author{
WU Yuan ${ }^{1}$, SONG WenLi ${ }^{1}$, ZHANG ZhongYan ${ }^{1}$, HUI XiDong ${ }^{1}$, MA Dong ${ }^{2}$, WANG XunLi ${ }^{2}$, \\ SHANG XinCun ${ }^{3} \&$ LU ZhaoPing ${ }^{1 *}$ \\ ${ }^{1}$ State Key Laboratory for Advanced Metals and Materials, University of Science and Technology Beijing, Beijing 100083, China; \\ ${ }^{2}$ Neutron Scattering Science Division, Oak Ridge National Laboratory, Oak Ridge, Tennessee 37831, USA; \\ ${ }^{3}$ Department of Mathematics and Mechanics, University of Science and Technology Beijing, Beijing 100083, China
}

Received July 25, 2011; accepted September 1, 2011

\begin{abstract}
Bulk metallic glass (BMG) composites with the austenite B2 phase as reinforcement macroscopically showed strain hardening behavior due to the plasticity induced by martensitic transformation during deformation. Relationship between characteristics of the B2-CuZr reinforcing phase and uniaxial compressive properties of CuZr-based BMG composites was studied. Mechanical properties of these BMG composites were found to depend on not only the reinforced phases but also the amorphous matrix, and the yield and fracture strength can be roughly estimated by the rule of mixture principle. Distribution of the reinforced $\mathrm{B} 2-\mathrm{CuZr}$ phase has an important impact on the compressive plasticity even for the composites with a similar volume fraction of the crystalline phase.
\end{abstract}

bulk metallic glass composites, transformation-induced plasticity, compressive mechanical properties

Citation: $\quad$ Wu Y, Song W L, Zhang Z Y, et al. Relationship between composite structures and compressive properties in CuZr-based bulk metallic glass system. Chinese Sci Bull, 2011, 56: 3960-3964, doi: 10.1007/s11434-011-4858-4

To overcome the Achilles's heel of bulk metallic glasses (BMGs), i.e., room temperature brittleness and strainsoftening, many approaches have been attempted [1-3]. Among which, formation of BMG composite structures has been proved to be an effective way in enhancing the roomtemperature plasticity, and large tensile ductility has been achieved by proper introduction of the dendritic reinforcing phases into Zr- or Ti-based BMGs [4-10]. However, these types of BMG composites still show the strain-softening behavior [9,10]. Recently, the concept of transformationinduced plasticity (TRIP) was applied into the $\left(\mathrm{Cu}_{0.5}\right.$ $\left.\mathrm{Zr}_{0.5}\right)_{100-x} \mathrm{Al}_{x}(x=1,2 \ldots . .10$ at $\%)$ BMG system and both tensile ductility and work-hardening capability were obtained [11-15]. The martensitic transformation of the $\mathrm{B} 2-\mathrm{CuZr}$ phase was found to be responsible for the enhanced tensile properties $[14,15]$.

However, the super-cooled austenitic $\mathrm{B} 2-\mathrm{CuZr}$ phase is

*Corresponding author (email: luzp@ustb.edu.cn) metastable which only exists above $988 \mathrm{~K}[16,17]$, and it has already been found that formation of the B2-CuZr phase is extremely sensitive to the composition and fabrication process [15]. On the other hand, it was also suggested that the volume fraction and distribution of the $\mathrm{B} 2-\mathrm{CuZr}$ phase both could affect the mechanical properties of the TRIPBMG composites [13,15]. However, the relationship between the characteristics of the B2 phase and macroscopic properties of these special BMG composites, and the contribution from the $\mathrm{B} 2$ phase to the work hardening are still needed further investigation. In this paper, we will focus on dependence of compressive deformation behavior on the characteristics of the $\mathrm{B} 2-\mathrm{CuZr}$ phase in the CuZr-based TRIP-BMG system.

\section{Experimental}

Alloy ingots with nominal compositions of $\left(\mathrm{Cu}_{0.5} \mathrm{Zr}_{0.5}\right)_{100-x} \mathrm{Al}_{x}$ 
$(x=3,4 \ldots \ldots 10$ at $\%)$ were prepared by arc-melting a mixture of constituent elements with a purity of above $99.9 \%$ in a Ti-gettered atmosphere. The alloy ingots were melted six times to ensure compositional homogeneity. Cylinder composite samples with different diameters were fabricated by suction casting using copper molds. Thermal properties were analyzed by differential scanning calorimetry (DSC) (Netzsch STA449C) at a rate of $10 \mathrm{~K} / \mathrm{min}$. Longitudinal and cross-section surfaces of the as-cast and strained samples were examined in a ZEISS SUPRA 55 scanning electron microscope (SEM). Volume fractions of crystalline phases were estimated from the SEM images with an Imagetool software. Compression samples with a diameter of $2 \mathrm{~mm}$ and a height of $4 \mathrm{~mm}$ were cut from the center of the as-cast rods. Uniaxial compression tests were conducted between two tungsten carbide platens at an engineering strain rate of $2 \times 10^{-4} \mathrm{~s}^{-1}$ in a SANS testing machine with a maximum load of $300 \mathrm{kN}$.

\section{Results}

\subsection{Effects of alloy compositions}

To study effects of the amorphous matrix which is closely associated with the alloy composition, samples of $\left(\mathrm{Cu}_{0.5}\right.$ $\left.\mathrm{Zr}_{0.5}\right)_{100-x} \mathrm{Al}_{x}(x=3, \ldots 10$, at $\%)$ with a diameter of $2 \mathrm{~mm}$ were fabricated, and X-ray diffraction results (not shown here) suggested that all these samples are fully amorphous. Compressive stress-strain curves of these amorphous samples with different $\mathrm{Al}$ contents are shown in Figure 1. As shown, alloys with a low $\mathrm{Al}$ content (i.e., $\leqslant 6 \%$ ) show considerable plasticity, whilst alloys with a large Al content (8\%) display a quasi-brittle fracture without any appreciable plasticity, strongly implying a dramatic change in the local atomic structure of these amorphous alloys. As the Al content increases, another distinct feature observed in Figure 1 is the notable increment in the yield strength. The $\mathrm{Cu}_{48.5} \mathrm{Zr}_{48.5} \mathrm{Al}_{3}$ alloy shows a yield strength of about $1700 \mathrm{MPa}$ while that of the $\mathrm{Cu}_{46} \mathrm{Zr}_{46} \mathrm{Al}_{8}$ alloy increases to about $1950 \mathrm{MPa}$.

It has been proposed that yield strength of metallic glasses has a close correlation with their glass transition temperature $\left(T_{\mathrm{g}}\right)[18,19]$. Thermal analysis of the

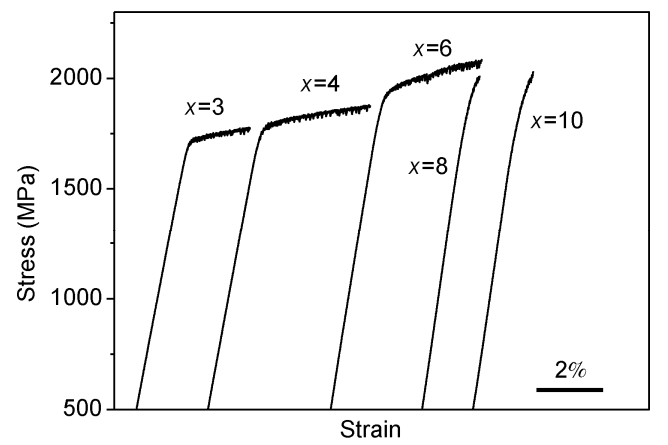

Figure 1 Compressive stress-strain curves of the $\left(\mathrm{Cu}_{0.5} \mathrm{Zr}_{0.5}\right)_{100-x} \mathrm{Al}_{x}$ amorphous samples with different $\mathrm{Al}$ contents.
$\left(\mathrm{Cu}_{0.5} \mathrm{Zr}_{0.5}\right)_{100-x} \mathrm{Al}_{x}(10 \geqslant x \geqslant 3)$ alloys with different casting diameters were also conducted. DSC traces of the $\mathrm{Cu}_{48} \mathrm{Zr}_{48} \mathrm{Al}_{4}$ and $\mathrm{Cu}_{47} \mathrm{Zr}_{47} \mathrm{Al}_{6}$ alloys are shown in Figure 2 as examples, and the measured thermal parameters are listed in Table 1. A distinct glass transition event was detected for all the specimens, even for those partially amorphous ones. The glass transition temperature $\left(T_{\mathrm{g}}\right)$ and the crystallization temperature $\left(T_{\mathrm{x}}\right)$ are almost unchanged for alloys with the same composition in spite of different casting diameters. These observations suggest that atomic structure of the glassy phase for the same alloy composition is not sensitive to the cooling rates studied. In contrast, the enthalpy of crystallization of the same alloy varies with different casting diameters, and a larger casting diameter (i.e., a lower cooling rate) gives rise to a smaller crystallization enthalpy, indicating a higher volume fraction of crystalline phases. It can also be easily seen that $T_{\mathrm{g}}$ and $T_{\mathrm{x}}$ of the $\mathrm{Cu}_{47} \mathrm{Zr}_{47} \mathrm{Al}_{6}$ alloy are higher than those of the $\mathrm{Cu}_{48} \mathrm{Zr}_{48} \mathrm{Al}_{4}$ alloy, showing an increase trend of $T_{\mathrm{g}}$ and $T_{\mathrm{x}}$ with the increase of Al. By taking the mean molar volume $\left(V_{\mathrm{m}}\right)$ of the current BMG alloy system as about $10.43 \mathrm{~cm}^{3} / \mathrm{mol}$ [20], the correlation between $T_{\mathrm{g}}$ and the yield strength of the current alloy system can be expressed as $\sigma_{\mathrm{y}}=50.05 \triangle T_{\mathrm{g}} / V_{\mathrm{m}}$, as shown in Figure 3, which is consistent with the empirical equation previously proposed by Yang et al. [18]. Additions of $\mathrm{Al}$ in the CuZr-based BMG can promote formation of dense localized packing clusters (e.g., icosahedrals) [21], which have a strong atomic bonding and large resistance to deformation, and

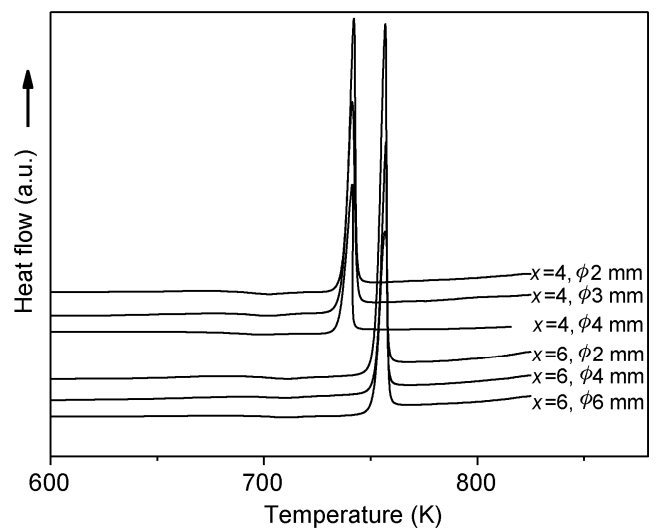

Figure 2 DSC curves of the $\mathrm{Cu}_{48} \mathrm{Zr}_{48} \mathrm{Al}_{4}$ and $\mathrm{Cu}_{47} \mathrm{Zr}_{47} \mathrm{Al}_{6}$ alloys with different casting diameters.

Table 1 Thermal parameters of the $\mathrm{Cu}_{48} \mathrm{Zr}_{48} \mathrm{Al}_{4}$ and $\mathrm{Cu}_{47} \mathrm{Zr}_{47} \mathrm{Al}_{6}$ alloys with different casting diameters

\begin{tabular}{cccccc}
\hline Alloys & $\begin{array}{c}\text { Casting diameter } \\
(\mathrm{mm})\end{array}$ & $T_{\mathrm{g}}(\mathrm{K})$ & $T_{\mathrm{x}}(\mathrm{K})$ & $\triangle T_{\mathrm{x}}(\mathrm{K})$ & $\begin{array}{c}\text { Crystallization } \\
\text { enthalpy }\left(\mathrm{J} \mathrm{g}^{-1}\right)\end{array}$ \\
\hline \multirow{2}{*}{$\mathrm{Al}=4 \%$} & 2 & 682.1 & 737.4 & 55.3 & 7.33 \\
& 3 & 682.7 & 736.6 & 53.9 & 6.90 \\
& 4 & 681.6 & 736.0 & 54.4 & 3.82 \\
$\mathrm{Al}=6 \%$ & 2 & 690.4 & 751.9 & 61.5 & 9.76 \\
& 4 & 690.4 & 752.5 & 62.1 & 7.12 \\
\hline
\end{tabular}


therefore increase the glass transition temperature and yield strength of the amorphous phase. Thus, it is reasonable to speculate that the composite with a higher $\mathrm{Al}$ content would possess a higher ultimate strength. Next, effects of the amorphous phase and crystalline phase on the macroscopic deformation behavior of the current BMG composites will be discussed in detail.

\subsection{Effects of phase selection}

It was known that the strength of BMG composites has a close correlation with type of the crystalline phases presented in the glassy matrix. In the present $\left(\mathrm{Cu}_{0.5} \mathrm{Zr}_{0.5}\right)_{100-x} \mathrm{Al}_{x}$ alloy system, it was found that characteristic of the precipitated crystallites were extremely sensitive to the composition and cooling rates applied during fabrication. For the as-cast samples with a $\mathrm{Al}$ content not more than $8 \%$, microstructure of the composites varies as follows: fully amorphous $\rightarrow$ amorphous+B2-CuZr $\rightarrow$ amorphous+B2-CuZr+ $\mathrm{Al}_{2} \mathrm{Zr}$ as the cooling rate decreases (i.e., the casting diameter increases) [15]. Figure 4 demonstrates the microstructure change of the cross-section of the as-cast $\mathrm{Cu}_{48} \mathrm{Zr}_{48} \mathrm{Al}_{4}$ alloy as a function of the casting diameter. When being cast in 3 or $4 \mathrm{~mm}$ rods, the alloy exhibited a composite structure with crystalline precipitates identified as bcc $\mathrm{B} 2-\mathrm{CuZr}$ phase with a volume fraction of about $15 \%$ and $45 \%$, respectively. Nevertheless, the B2-CuZr phase in the $4 \mathrm{~mm}$ as-cast rods combined with each other to form patch-like morphology across the amorphous matrix. With the further decrease of the cooling rate, in addition to the spherical $\mathrm{B} 2$ phase, another phase, the intermetallic compound $\mathrm{Al}_{2} \mathrm{Zr}$ was formed, which are shown in Figure 4(e) and (f).

Along with the variation in the microstructure, the compressive behavior changed accordingly. Figure 5(a) shows the compressive stress-strain curves of the $\mathrm{Cu}_{48} \mathrm{Zr}_{48} \mathrm{Al}_{4}$ alloys with different casting diameters. To avoid the so-called "size effect" [22,23], all the testing samples were cut from the center part of the as-cast rods and had a diameter of 2 $\mathrm{mm}$. For the fully amorphous sample, a typical stress-strain

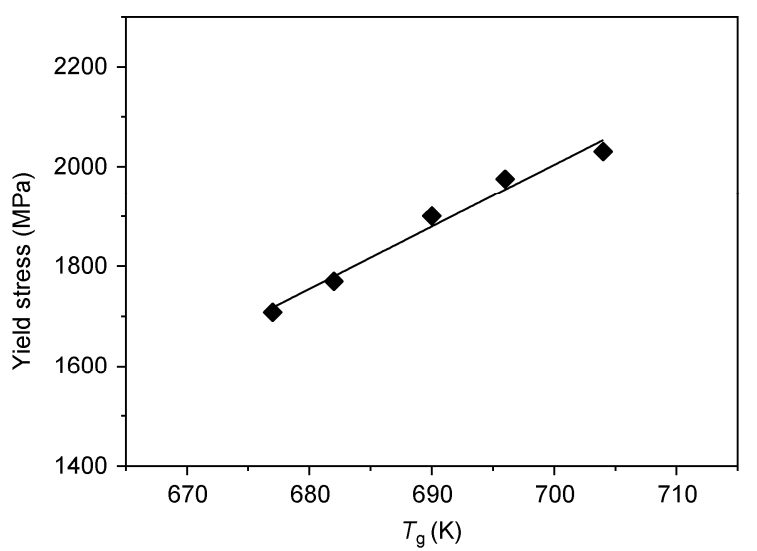

Figure 3 Dependence of yield strength on the glass transition temperature of the $\left(\mathrm{Cu}_{0.5} \mathrm{Zr}_{0.5}\right)_{100-x} \mathrm{Al}_{x} \mathrm{BMG}$ alloys.

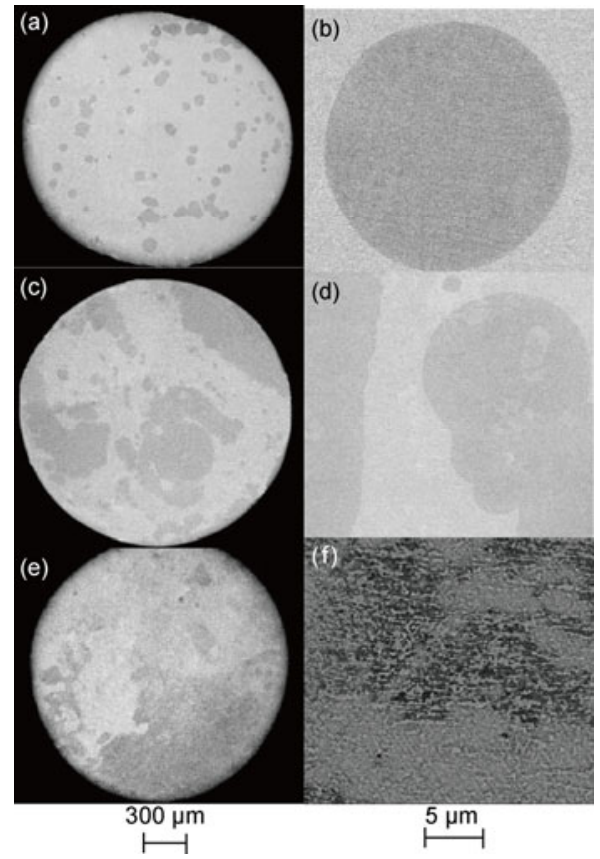

Figure 4 SEM images of the $\mathrm{Cu}_{48} \mathrm{Zr}_{48} \mathrm{Al}_{4}$ alloy cut from rods with different casting diameters. (a) $d=3 \mathrm{~mm}$, (c) $d=4 \mathrm{~mm}$, (e) $d=5 \mathrm{~mm}$. Images (b), (d) and (f) are the enlargements of (a), (c) and (e), respectively.

curve with serration flows is observed. For the sample cut from the $3 \mathrm{~mm}$ rods, the compressive plasticity and the ultimate fracture strength are remarkably increased. It is interesting to note that at the early stage of the plastic deformation, no distinct serration flow was seen, indicating a change in deformation mode. For the sample cut from the 4 $\mathrm{mm}$ rods, the stress-strain curve exhibits a much lower yield strength and smaller plasticity but a more pronounced work-hardening behavior. For the sample cut from $5 \mathrm{~mm}$ rods, the compressive stress-strain curve displays a very low yield strength of about $300 \mathrm{MPa}$, a fracture strain of no more than $5 \%$ and fracture strength of no more than 1500 MPa. The specimen broke into several pieces after fracture, exhibiting a brittle deformation mode. It can be seen that compressive plasticity of the sample cut from the $3 \mathrm{~mm}$ as-casts (around 15\% B2-CuZr phase) was remarkably increased without deteriorating the strength. With more B2-CuZr phase present, the composites possess a low yield strength but a similar facture strength. However, if any brittle phases like $\mathrm{Al}_{2} \mathrm{Zr}$ precipitates, the composites became extremely brittle without any plasticity.

True stress-strain curves of several other alloys with different $\mathrm{Al}$ additions are illustrated in Figure 5(b), and a similar dependence of deformation behavior on the cooling rates was also observed. In general, compressive deformation behavior of the current composite system can be categorized into three types. For the BMG composites containing $\mathrm{Al}_{2} \mathrm{Zr}$ phase, appreciably low strength and plasticity can be seen. For the specimens with a volume fraction of $10 \%-30 \%$ B2 crystals homogenerously distributed in the amorphous matrix, high yield strength and distinct work-hardening can be 

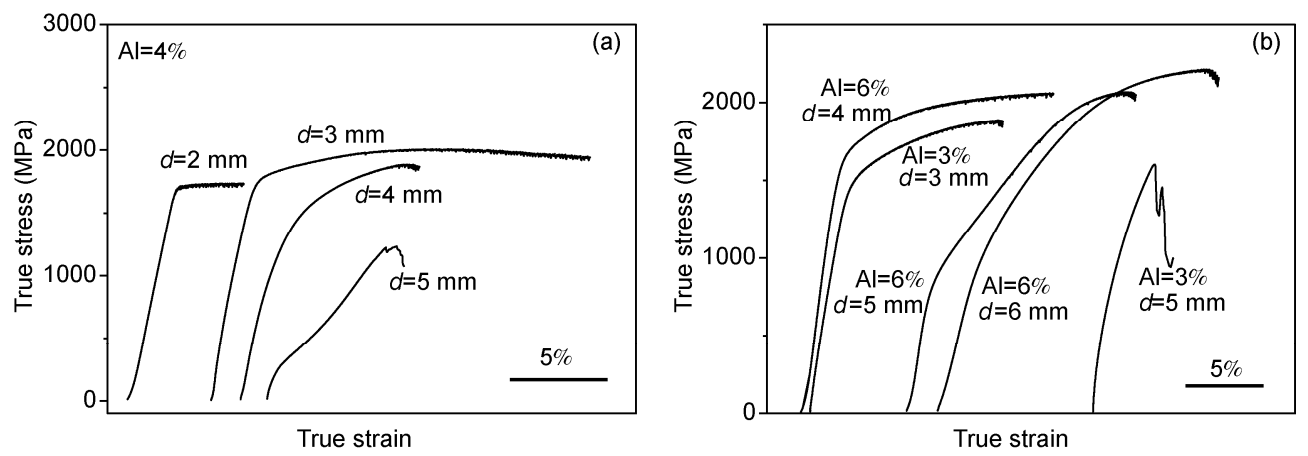

Figure 5 Uniaxial compressive true stress-strain curves of (a) the $\mathrm{Cu}_{48} \mathrm{Zr}_{48} \mathrm{Al}_{4}$ alloy with different casting diameters, and (b) the other BMG composites.

observed. As the B2 crystals are increased to more than $40 \%$, however, the specimens initially yielded at a much lower stress but underwent a more pronounced workhardening behavior and subsequently the second yielding. The double yielding phenomenon could be linked to a change in the deformation mechanism from being borne by a martensitic transformation to a process mediated by dislocation movement [24].

\subsection{Effects of volume fractions of the B2 phase}

Volume fractions of the crystal phase were found to severely affect mechanical properties in the dendrites reinforced composite $[9,10,25]$. Crystalline volume fractions can be varied by changing the applied cooling rates (i.e., the casting diameter) during fabrication of the composites and the longitudinal position of the as-cast rods. By properly adjusting the fabrication process, composite specimens of the $\mathrm{Cu}_{48} \mathrm{Zr}_{48} \mathrm{Al}_{4}$ alloy with different crystalline volume fractions were fabricated and tested under uniaxial compression, and the corresponding values of the yield strength, fracture strength and fracture strain are listed in Table 2. Variation of the yield strength and fracture strength with volume fractions of the B2-CuZr phase was shown in Figure 6. As the volume fraction of $\mathrm{B} 2-\mathrm{CuZr}$ increases, the yield strength gradually decreases. It was known that yield strength of composite materials can usually be estimated from properties of the constituent phases by the rule of mixtures (ROM) principle. With the yield strength of the amorphous matrix and pure $\mathrm{B} 2-\mathrm{CuZr}$ phase [24], the estimated values of these BMG composites are also shown as the dashed line in Figure 6. It can be seen that the variation trend of the experimental data roughly agrees with the predication by the ROM principle. It is worthy to be noted that the above trend observed in the present experiment is not consistent with previous report [13], which may arise from different distribution of the B2-CuZr phase. Unlike the yield strength, the fracture strength hovers around $2100 \mathrm{MPa}$. Full B2-CuZr materials have a relatively low yield strength of about 470 $\mathrm{MPa}$ but a high fracture strength of about $2100 \mathrm{MPa}$ which is close to that of the amorphous matrix [24]. Therefore, different volume fractions of the $\mathrm{B} 2$ phase have dramatic
Table 2 Yield strength, fracture strength and fracture strain of $\mathrm{Cu}_{48} \mathrm{Zr}_{48} \mathrm{Al}_{4} \mathrm{BMG}$ composites with different crystalline volume fractions

\begin{tabular}{cccc}
\hline $\begin{array}{c}\text { Crystalline } \\
\text { volume fraction }(\%)\end{array}$ & $\begin{array}{c}\text { Yield strength } \\
(\mathrm{MPa})\end{array}$ & $\begin{array}{c}\text { Fracture } \\
\text { strength }(\mathrm{MPa})\end{array}$ & $\begin{array}{c}\text { Fracture strain } \\
(\%)\end{array}$ \\
\hline 0.3 & 1598 & 2038 & 6.1 \\
2.5 & 1653 & 2087 & 11.6 \\
2.5 & 1656 & 1963 & 16.2 \\
4.7 & 1770 & 2077 & 10.3 \\
5.2 & 1651 & 2010 & 15.6 \\
7.0 & 1563 & 2067 & 7.1 \\
8.8 & 1669 & 2040 & 7.9 \\
8.9 & 1751 & 2205 & 10.0 \\
9.8 & 1619 & 1994 & 5.1 \\
9.9 & 1626 & 2238 & 21.7 \\
19.6 & 1592 & 2210 & 14.5 \\
20.2 & 1567 & 2075 & 10.3 \\
24.0 & 1538 & 2109 & 7.8 \\
26.2 & 1348 & 2084 & 10.3 \\
\hline
\end{tabular}

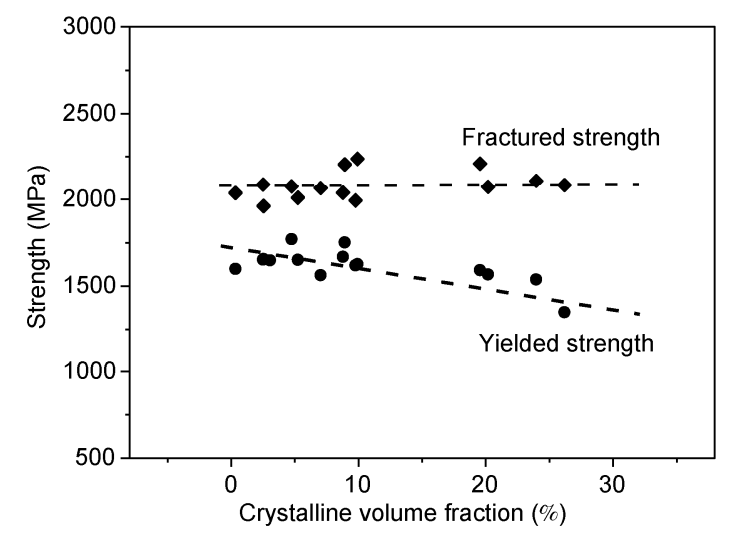

Figure 6 Variation of the yield and fractured strength with volume fraction of reinforced $\mathrm{B} 2$ phase in $\mathrm{Cu}_{48} \mathrm{Zr}_{48} \mathrm{Al}_{4}$ BMG composites.

effects on the yield strength but not the fracture strength.

\subsection{Effects of distribution of the $\mathrm{B} 2$ phase}

Even for the BMG composites with a similar crystalline volume fraction, the fracture strain may vary tremendously due to different distribution of the reinforcing phase. As an example, Figure 7 shows the stress-strain curves of three BMG composites with $\sim 10 \% \mathrm{~B} 2$ phase for the $\mathrm{Cu}_{48} \mathrm{Zr}_{48} \mathrm{Al}_{4}$ alloy. Surprisingly, the fracture strain changes dramatically from $6 \%$ to $22 \%$. SEM images in Figure 7 indicate that all 


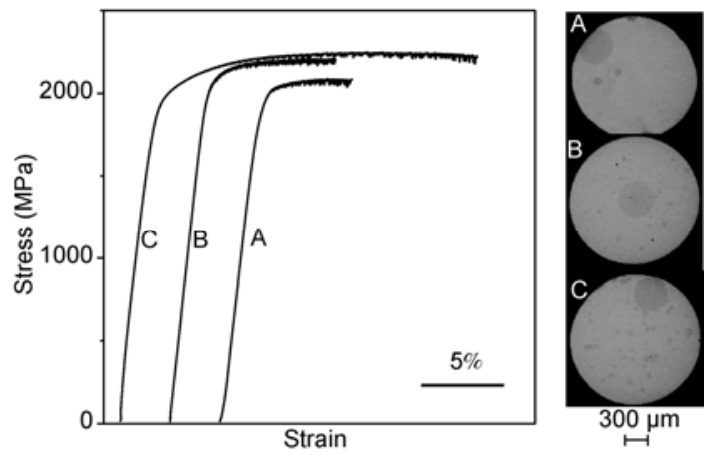

Figure 7 Compressive true stress-strain curves of the $\mathrm{Cu}_{48} \mathrm{Zr}_{48} \mathrm{Al}_{4}$ alloy with about $10 \%$ B2 phase, and SEM images of the three samples with a similar crystal volume fraction of B2 phase but different distribution pattern.

the three samples contain one large spherical crystal and some small spherical crystals. Specimen A has only four small crystals, whilst $B$ and $C$ have more tiny crystals which are distributed more homogeneously in specimen C. As can be seen, homogeneous distribution of the B2 phase gives rise to a large fracture strain, manifesting that distribution of the reinforced crystals also play important roles in obtaining macroscopic plasticity of the current BMG composites.

\section{Conclusions}

Mechanical properties of the current CuZr-based TRIP BMG composite were found to have a close relationship with characteristics of the B2-CuZr phase. Strength of the amorphous phase increases with additions of $\mathrm{Al}$, which has large influences on the fracture strength of the BMG composites. BMG composites with single $\mathrm{B} 2-\mathrm{CuZr}$ phase as reinforcement possess better mechanical properties as compared with those containing $\mathrm{Al}_{2} \mathrm{Zr}$. With the increase of B2-CuZr phase, the yield strength of the present composites decreases but the fracture strength is almost unchanged, which can be roughly explained by the role of mixture principle. Besides the volume fraction, distribution of the reinforcing B2 phase also strongly affects the fracture strain and homogeneous distribution favors a large fracture strain.

This work was supported in part by the National Natural Science Foundation of China (50725104, 51010001 and 51001009), China Postdoctoral Science Foundation (20100470208) and "the Fundamental Research Funds for the Central Universities (FRF-BR-10-036B)".

1 Schuh C A, Hufnagel T C, Ramamurty U. Mechanical behavior of amorphous alloys. Acta Mater, 2007, 55: 4067-4109

2 Chen M W. Mechanical behavior of metallic glasses: Microscopic understanding of strength and ductility. Annu Rev Mater Res, 2008, 38: $445-469$

3 Ashby M F, Greer A L. Metallic glasses as structural materials. Scripta Mater, 2006, 54: 321-326
4 Conner R D, Dandliker R B, Johnson W L. Mechanical properties of tungsten and steel fiber reinforced $\mathrm{Zr}_{41.25} \mathrm{Ti}_{13.75} \mathrm{Cu}_{12.5} \mathrm{Ni}_{10} \mathrm{Be}_{22.5}$ metallic glass matrix composites. Acta Mater, 1998, 46: 6089-6102

5 Fan C, Li H Q, Kecskes L J, et al. Mechanical behavior of bulk amorphous alloys reinforced by ductile particles at cryogenic temperatures. Phys Rev Lett, 2006, 96: 145506

6 Hays C C, Kim C P, Johnson W L. Microstructure controlled shear band pattern formation and enhanced plasticity of bulk metallic glasses containing in situ formed ductile phase dendrite dispersions. Phys Rev Lett, 2000, 84: 2901-2904

7 Guo S F, Liu L, Li N, et al. Fe-based bulk metallic glass matrix composite with large plasticity. Scripta Mater, 2010, 62: 329-332

8 Wu F F, Zhang Z F, Mao S X, et al. Effect of annealing on the mechanical properties and fracture mechanisms of a $\mathrm{Zr}_{56.2} \mathrm{Ti}_{13.8} \mathrm{Nb}_{5.0}$ $\mathrm{Cu}_{6.9} \mathrm{Ni}_{5.6} \mathrm{Be}_{12.5}$ bulk-metallic-glass composite. Phys Rev B, 2007, 75: 134201

9 Hofmann D C, Suh J Y, Wiest A, et al. Designing metallic glass matrix composites with high toughness and tensile ductility. Natrue, 2008, 451: 1085-1089

10 Hofmann D C, Suh J Y, Wiest A, et al. Development of tough, low-density titanium-based bulk metallic glass matrix composites with tensile ductility. Proc Natl Acad Sci USA, 2008, 105: 2013620140

11 Pauly S, Das J, Bednarcik J, et al. Deformation-induced martensitic transformation in $\mathrm{Cu}-\mathrm{Zr}$-(AlTi) bulk metallic glass composites. Scripta Mater, 2009, 60: 431-434

12 Sun Y F, Wei B C, Wang Y R, et al. Plasticity-improved Zr-Cu-Al bulk metallic glass matrix composites containing martensite phase. Appl Phys Lett, 2005, 87: 051905

13 Pauly S, Liu G, Wang G, et al. Modeling deformation behavior of Cu-Zr-Al bulk metallic glass matrix composites. Appl Phys Lett, 2009, 95: 101906

14 Wu Y, Xiao Y H, Chen G L, et al. Bulk metallic glass composites with transformation-mediated work-hardening and ductility. Adv Mater, 2010, 22: 2770-2773

15 Wu Y, Wang $\mathrm{H}$, Wu H H, et al. Formation of $\mathrm{Cu}-\mathrm{Zr}$-Al bulk metallic glass composites with improved tensile properties. Acta Mater, 2011, 59: $2928-2936$

16 Koval Y N, Firstov G S, Kotko A V. Martensitic transformation and shape memory effect in $\mathrm{ZrCu}$ intermetallic compound. Scripta Mater, 1992, 27: 1611-1616

17 Seo J W, Schryvers D. TEM investigation of the microstructure and defects of CuZr martensite. Part 1: Morphology and twin systems. Acta Mater, 1998, 46: 1165-1175

18 Yang B, Liu C T, Nieh T G. Unified equation for the strength of bulk metallic glasses. Appl Phys Lett, 2006, 88: 221911

19 Xiao Y H, Wu Y, Liu Z Y, et al. Effects of cooling rates on the mechanical properties of a Ti-based bulk metallic glass. Sci China Phys Mech Astron, 2010, 53: 394-398

20 Wang J Q, Wang W H, Bai H Y. Distinguish bonding characteristic in metallic glasses by correlations. J Non-Cryst Solids, 2011, 357: 220-222

21 Peng H L, Li M Z, Wang W H. Structural signature of plastic deformation in metallic glasses. Phys Rev Lett, 2011, 106: 135503

22 Wu Y, Li H X, Liu Z Y, et al. Interpreting size effects of bulk metallic glasses based on a size-independent critical energy density. Intermetallics, 2010, 18: 157-160

$23 \mathrm{Wu} \mathrm{Y,} \mathrm{Li} \mathrm{H} \mathrm{X,} \mathrm{Jiao} \mathrm{Z} \mathrm{B,} \mathrm{et} \mathrm{al.} \mathrm{Size} \mathrm{effects} \mathrm{on} \mathrm{compressive} \mathrm{defor-}$ mation behavior of a brittle Fe-based bulk metallic glass. Philo Mag Lett, 2010, 90: 403-412

24 Pauly S, Bednarcik J, Kuhn U, et al. Plastically deformable Cu-Zr intermetallics. Scripta Mater, 2010, 63: 336-338

25 Qiu S B, Yao K F, Gong P. Effects of crystallization fractions on mechanical properties of $\mathrm{Zr}$-based metallic glass matrix composites. Sci China Phys Mech Astron, 2010, 53: 424-429

Open Access This article is distributed under the terms of the Creative Commons Attribution License which permits any use, distribution, and reproduction in any medium, provided the original author(s) and source are credited. 